Research Article

\title{
Inspection of the Spark Plug Effect NGK Nanoparticle on the Dielectric Properties of Filled Polyvinyl Chloride Paste Resin
}

\author{
Abdullah Hussein $^{1}$, Tahseen Alaridhee ${ }^{2}$, Forat Yasir AlJaberi ${ }^{3}$ \\ ${ }^{1}$ Department of Material Science, Polymer Research Center, University of Basrah, Basrah, Iraq. \\ ${ }^{2}$ Department of Physics, College of Education for Pure Science, University of Basrah, Basrah, Iraq. \\ ${ }^{3}$ Department of Chemical Engineering, College of Engineering, Al-Muthanna University, Al-Muthanna, Iraq. \\ C Corresponding author. E-mail: abdullah28977@gmail.com Tel.: +9647801078688
}

Received: Mar. 18, 2020; Accepted: May 14, 2020; Published: Jun. 4, 2020

Citation: Abdullah Hussein, Tahseen Alaridhee, and Forat Yasir AlJaberi, Inspection of the Spark Plug Effect NGK Nanoparticle on the Dielectric Properties of Filled Polyvinyl Chloride Paste Resin. Nano Biomed. Eng., 2020, 12(2): I84- 190.

DOI: 10.5101/nbe.v12i2.p184-190.

\begin{abstract}
In this study, the investigation of the use of polyvinyl chloride-paste (PVC-P) composites which contained spark plug aluminum silicate nanoparticles (NGK-NPs) for different insulation applications was carried out. The spark plug NGK-NPs acted as a matrix for the aluminum silicate nanoparticle powder. We analyzed the dielectric properties of the PVC-P / NGK-NPs composite material for the function of its filler content, temperature and frequency. We also studied the AC conductivity and impedance of the composite. Results indicated that the dielectric loss, dielectric constant and the loss tangent of the composites increased with an increase in the NGK-NPs filler content.
\end{abstract}

Keywords: Dielectric properties; Polyvinyl; NGK-NPs; Nanoparticle filler

\section{Introduction}

Polymeric composites containing inorganic fillers were used in many electronic and electrical applications. These systems were characterized to be heterogeneous and their different electrical characteristics were dependent on factors like size, shape, volume fraction, the conductivity of the filler, processing technique and the adhesion between filler and polymer materials. The main advantage of using these composites was that they exhibited compatible and better properties which were could not be displayed by the constituent materials [1-4].

Fillers tend to improve the thermal, mechanical and electrical (i.e., permittivity and conductivity) properties of the composites. They decrease the shrinking and are cost-effective. Furthermore, for developing polymer-matrix composites that displayed better electrical insulation and thermal conductivity, the researchers used fillers (such as boron nitride, diamond, aluminum nitride, alumina, fused $\mathrm{SiO}_{2}$, silicon carbide and beryllium oxide) [5-8]. Some studies used metallic fillers, graphite and carbon black for enhancing the thermal and electrical properties of the fillers [8-10]. Nonconductive fillers were noted to improve the dielectric permittivity owing to interfacial polarization (i.e., Maxwell-Wagner-Sillars polarization). The dielectric permittivity and electrical conductivity of the composite fillers increased with an increase in the filler volume fractions. This continued 
until any drastic changes in the properties reached a critical filler concentration known as a percolation threshold. The use of the composites was dependent on their capability to disperse the filler molecules homogeneously uniformly in the material [11]. The PVC-P composites contain the poly vinyl chloridepaste resin along with a conductive/non-conductive filler. These composites display very interesting properties and are used for several applications like thin-film coating, encapsulating, electromagnetic frequency interference shields, packaging of electronic circuits, antistatic devices, protective coatings and thermistors [12-14].

In the past few years, the research in the PVC-P resin-based composite dielectric systems has garnered a lot of interest owing to their interesting electrical properties [15, 16]. These properties have been attributed to the complex motion of the molecules in the molecular matrix. Hence, investigating the dielectric loss, A.C. conductivity and dielectric constant, as the function of frequency and temperature was regarded as a sensitive technique for understanding the polymer structure. Here, we used PVC-P resin as the matrix and used the alumina silicate NGKNPs $\left(\mathrm{SiO}_{2}\right.$ and $\left.\mathrm{Al}_{2} \mathrm{O}_{3}\right)$ powder as the filler composite. We investigated the dielectric properties of these composites as the function of the filler weight function, frequency and temperature. We also studied the impedance and A.C. conductivity.

\section{Experimental Materials and methods}

In this study, we selected a commercial PVC-P resin (717-heavy duty-clear) due to its effective dielectric properties $\left(\varepsilon^{\prime}=3.19\right.$, $\tan \theta=0.002$ ), dielectric strength 544 volts/mil, glass transition temperature $\left(\mathrm{T}_{\mathrm{g}}\right)=$ $75^{\circ} \mathrm{C}$, and density $=1.42 \mathrm{gm} / \mathrm{cm}^{3}$. This resin was purchased from Swan Trading Company (L.L.C). We also acquired the solvent-borne PVC-P resin-based cement which was best suited for PVC-P pipe joining. This cement could be used for developing natural gas pipes, portable water irrigation, conduit, drain, etc. We also purchased the alumina silicate nanoparticle (NGKNPs) ceramic powder (grain size of $\approx 80 \mathrm{~nm}$; density of $5.8 \mathrm{gm} / \mathrm{cm}^{3}$ ) from the local market and used it as the filler.

\section{Sample preparation}

To ensure that the filler was uniformly dispersed, and a homogeneous composite was obtained, different concentrations of the NGK-NPs powder (5, 10, 15, 20 and 25\% wt.\%) to the PVC-P resin was added. This mixture was blended with the help of using the Petri dish mixer for $10 \mathrm{~min}$ at $70{ }^{\circ} \mathrm{C}$. This mixture was cast as a thick film on the clean $\mathrm{Al}$ substrates. Thereafter, they carried out the initial curing for $24 \mathrm{~h}$ at room temperature, followed by the post-curing for $2 \mathrm{~h}$ at $120^{\circ} \mathrm{C}$. Then, circular, thick disk-shaped film aluminum electrodes (diameter of $6 \mathrm{~mm}$ and $2.5 \mathrm{~cm}$ sheet) were vacuum deposited on the upper regions of the casted composites. Finally, a sandwich containing $\mathrm{Al} /$ thermosetting sheets made of composite/Al was developed. These films were placed between 2 stainless steel gold-coated electrodes. The measurements of the dielectric constant and the tangent loss were conducted in a frequency range of $120 \mathrm{~Hz}$ and $1 \mathrm{kHz}$ at $25^{\circ} \mathrm{C}$.

\section{Characterization and measurements}

The measurement of the dielectric values of the above-mentioned composite samples was carried out using the Hewlett Packard 4284 A-Impedance Analyzer. All film samples $(20 \mathrm{~mm}$ diameter and $1 \mathrm{~mm}$ thickness) were rested between the steel electrodes. Thereafter, the loss tangent and permittivity values were measured for the frequency values ranging between 100 and $106 \mathrm{~Hz}$ (fixed temperature of $25^{\circ} \mathrm{C}$ ) and temperature values ranging between 30 and $120^{\circ} \mathrm{C}$ (fixed frequency of $1 \mathrm{kHz}$ ). The following formula was used for calculating the relative complex permittivity $\left(\varepsilon^{*}\right)$ :

$\varepsilon^{*}=\varepsilon^{\prime}-\mathrm{i} \varepsilon^{\prime \prime}$.

Here, $I=\sqrt{ }-1 . \varepsilon^{\prime}$ and $\varepsilon^{\prime \prime}$ denoted the real and the imaginary components of the relative permittivity, respectively. The dielectric loss for the permittivity was calculated using the values of the loss tangent and Capacitance $[17,18]$. The actual correlation between the Capacitance, $\mathrm{C}$ and real permittivity, $\left(\varepsilon^{\prime}\right)$, values of a ferrite sample was estimated as follows:

$\mathrm{C}=\varepsilon_{0} \varepsilon^{*} \mathrm{~A} / \mathrm{d}$,

and

$\varepsilon^{\prime \prime}=\varepsilon^{\prime} \tan \delta$.

Wherein, $\mathrm{d}=$ separation distance between the electrodes; $\mathrm{A}=$ area of the electrodes, and $\varepsilon_{0}$ is the permittivity of free space that equals to $8.85 \times 10^{-12} \mathrm{~F} /$ $\mathrm{m}$. The A.C. conductivity $\left(\sigma_{\text {a.c }}\right)$ was estimated using the following formula $[19,20]$ :

$\sigma_{\text {a.c }}=\varepsilon_{0} \omega \varepsilon^{\prime \prime}$. 
Wherein; $\omega=$ angular frequency. The following formula was used for determining the complex impedance $\left(Z^{*}\right)$ value:

$\mathrm{Z}^{*}=\mathrm{Z}+i \mathrm{Z}^{\prime}$.

$\mathrm{Z}$ and $\mathrm{Z}^{\prime}$ were the real and imaginary components of impedance, respectively. The real impedance values, $\mathrm{Z}$, at differing frequencies (up to $500 \mathrm{kHz}$ ) were measured using the impedance analyzer (Hewlett Packard A4800).

\section{Results and Discussion}

Fig. 1 shows the dielectric permittivity $\left(\varepsilon^{\prime}\right)$ for the PVC-P/NGK-NPs composites as the function of the NGK-NPs powder for 2 fixed frequency values, i.e., $120 \mathrm{~Hz}$ and $1 \mathrm{kHz}$ at room temperature. It was noted that the addition of NGK-NPs filler to the polymers increased the value of permittivity of the composite, which increased with an increase in the NGK-NPs filler content. This direct increase in the permittivity value was based on an increase in the filler content, and was related to the interfacial polarization or the MaxwellWagner Sillars (MWS) value as noted to have occurred between the PVC-P matrix and NGK-NPs particles [15-17].

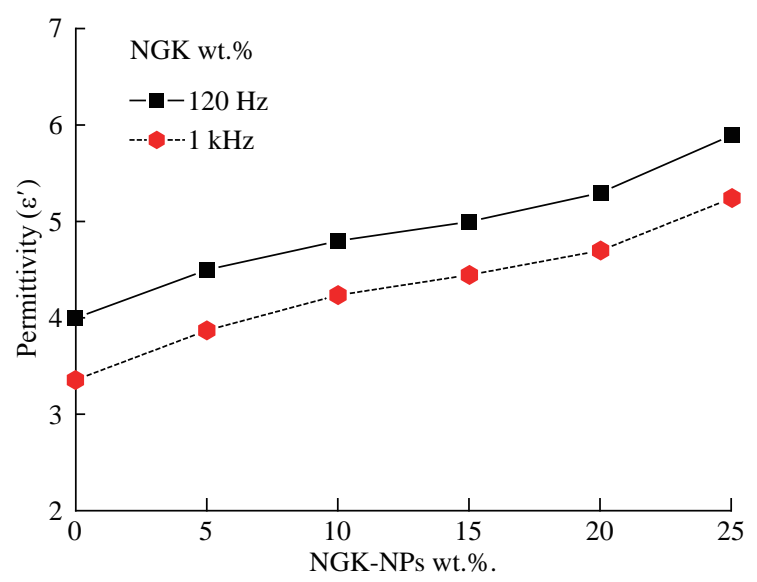

Fig. 1 The permittivity as a function of filler content for 2 different frequencies.

Fig. 2 shows the temperature dependence of the dielectric permittivity $\left(\varepsilon^{\prime}\right)$ value for different temperature values ranging between 30 and $110{ }^{\circ} \mathrm{C}$ at a fixed electric field frequency value of $1 \mathrm{kHz}$ for the PVC-P/NGK-NPs composites. The results indicated that the permittivity increased with an increasing temperature value.

This was attributed to the increase in the segmental

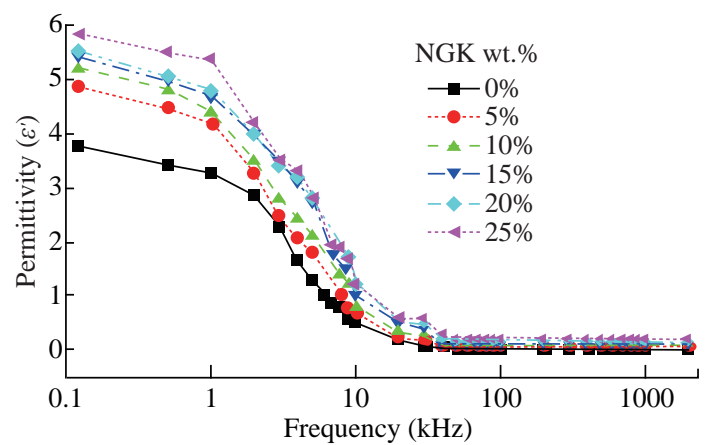

Fig. 2 The variation of dielectric permittivity of PVC-P/NGKNPs composites with temperature and filler content.

mobility of the dipoles within the matrix (the dipole molecular chains of the polymers had greater freedom of movement at a higher temperature) and the changes occurring in the dielectric response of filler particles as a function of temperature [18]. As depicted in Fig. 3 , the dependence of the dielectric permittivity $\left(\varepsilon^{\prime}\right)$ values of the PVC-P/NGK-NPs composites on the different frequency values, ranging between $120 \mathrm{~Hz}$ and $2 \mathrm{MHz}$ for varying weight fractions of NGK-NPs at room temperature. The dielectric permittivity value decreased with an increase in the frequency values for all filler contents. Furthermore, it was seen that a reduction in the dipolar polarization of this matrix and an accumulation of the charges at the interface of the filler particles and the polymer led to a large-scale field distortion [19]. This change decreased at frequency values above $100 \mathrm{kHz}$.

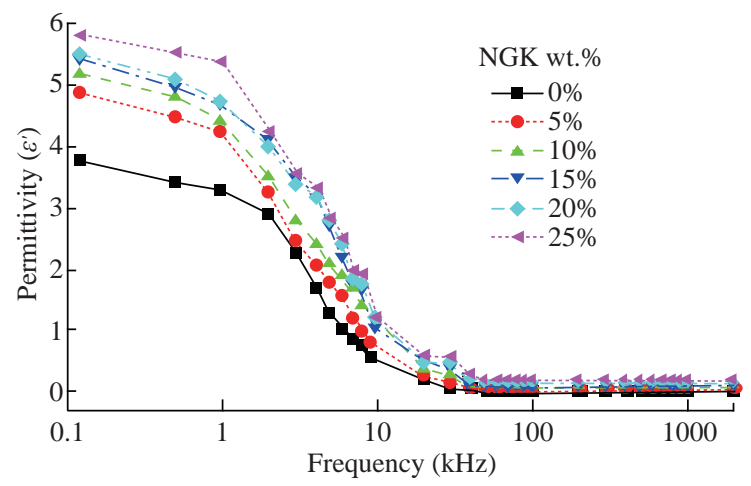

Fig. 3 The variation of dielectric permittivity of PVC-P/NGKNPs composites with frequency and filler content.

In Fig. 4, the changing dielectric loss factor ( $\left.\varepsilon^{\prime \prime}\right)$ was noted for the PVC-P/NGK-NPs composites, as the function of the filler weight fractions and temperatures, at the constant frequency of $1 \mathrm{kHz}$ that was applied to the field. It was seen that the dielectric loss factor increased with increasing temperature and filler content. The increasing dielectric loss that was 


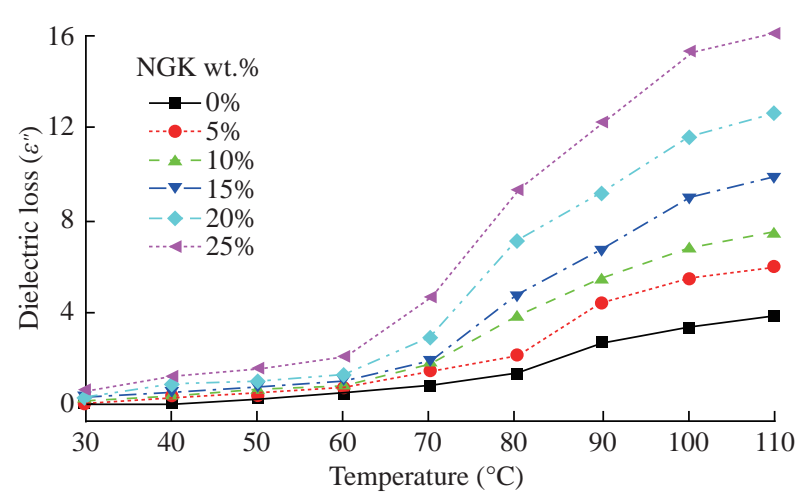

Fig. 4 The variation of dielectric loss factor of PVC-P/NGKNPs composites with temperature and filler content.

noted with increasing temperatures was related to the tendency of the dipole molecules to rotate in the electric field and overcome the internal frictional forces between the molecular frictions or intermolecular interactions, which led to an expenditure of some electrical energy or its conversion to thermal energy [20].

The variations occurred in the dielectric loss values $\left(\varepsilon^{\prime \prime}\right)$ at different frequency values ranging between $120 \mathrm{~Hz}$ and $2 \mathrm{MHz}$ at room temperature for different samples (Fig. 5). This frequency dependency is known as dielectric relaxation as it is characterized by relaxation time, $\tau$, or the relaxation frequency, $\mathrm{f}_{\mathrm{o}}$, which corresponds to $\Delta \varepsilon / 2$. This relaxation shifts to the lower frequencies when the NGK-NPs content increases. A gradual increase in the dielectric loss value was noted when the frequency value increased until it reached a maximal value. This increase in the dielectric loss was related to the A.C. conductivity $\left(\sigma_{\mathrm{a} . \mathrm{c}}\right)$ that was dependent on the number of charge carriers, frequency domain and relaxation time. The dielectric loss value showed a gradual decrease when the temperature value

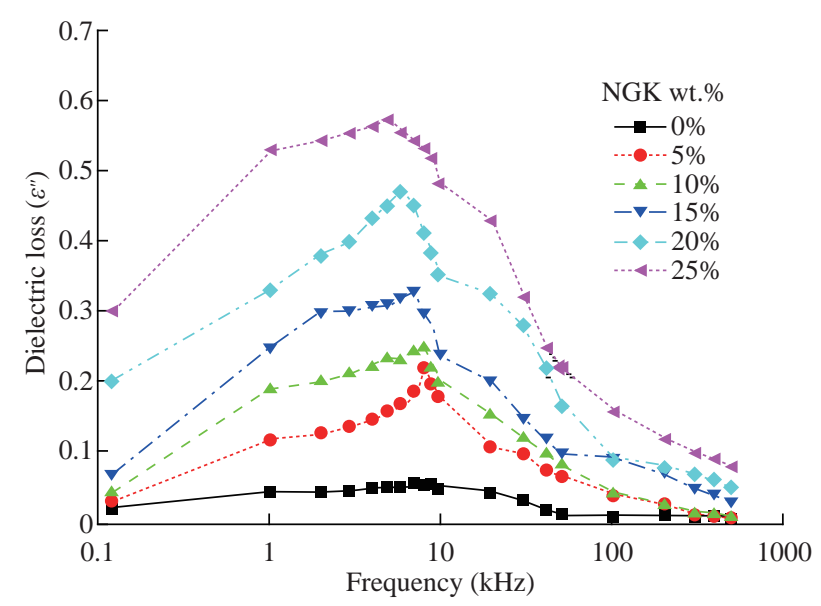

Fig. 5 The variation of dielectric loss factor of PVC-P/NGKNPs composites with frequency and filler content. was maintained as constant. The relaxation process was affected by the interfacial polarization [21, 22].

Fig. 6 presents the plots for the relaxation time $(\tau)$ versus NGK-NPs powder content. The results presented in the figure indicated that the relaxation time increased with an increase in the filler content. This was related to the increase in the A.C. conductivity and was attributed to the interfacial or MWS polarization seen in a complex system which exhibited electrical heterogeneity, because of the accumulation of the charges at the system interface [23].

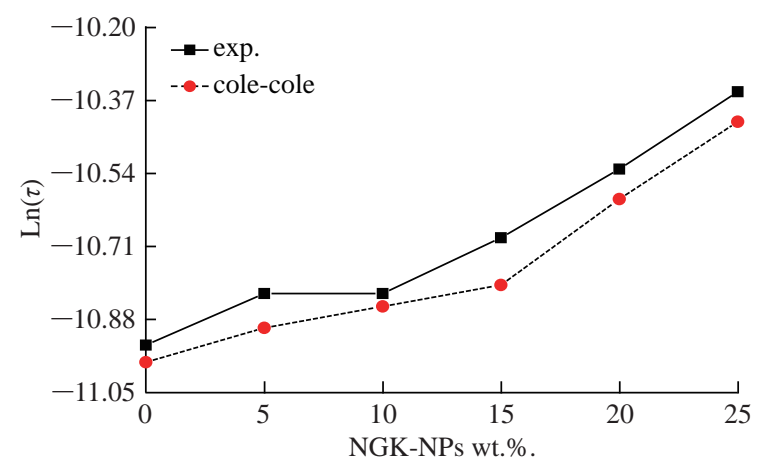

Fig. 6 Relaxation time of the filler content on PVC-P/NGK-NPs composites.

The relationship between the dielectric loss $\left(\varepsilon^{\prime \prime}\right)$ as the function of dielectric permittivity $\left(\varepsilon^{\prime}\right)$ for the PVC-P/NGK-NPs composites at room temperature is presented in Fig. 7. We used the Cole-Cole plot for estimating the generalized relaxation time, which was related to the distribution of all relaxation times. All the values for the relaxation time are collected in Table 1.

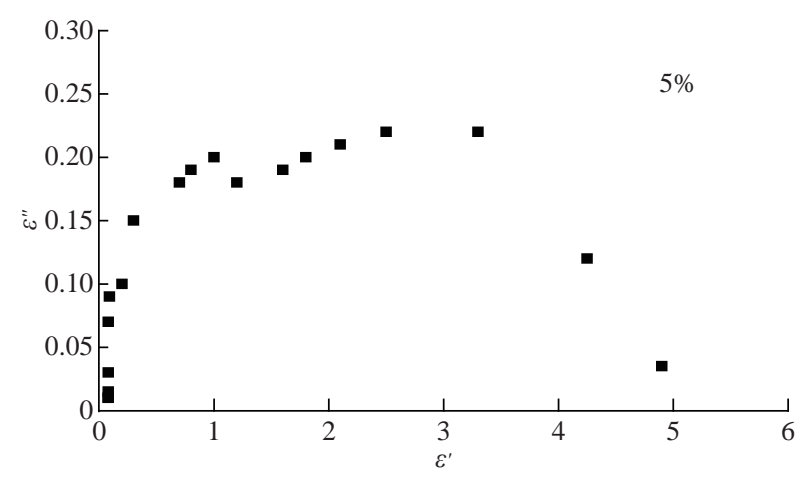

Fig. 7 Relaxation time of the filler content on PVC-P/NGK-NPs composites.

Table 1 The relaxation time for PVC-P/NGK-NPs composites

\begin{tabular}{ccccccc}
\hline wt. $\%$ & 0 & 5 & 10 & 15 & 20 & 25 \\
\hline $\mathrm{t}\left(\mathrm{sec} . * 10^{-5}\right)$ & 1.7 & 1.88 & 2.14 & 2.61 & 3 & 3.7 \\
\hline
\end{tabular}


Fig. 8 describes the temperature dependence of the A.C. conductivity for varying temperatures (ranging from 30 to $110{ }^{\circ} \mathrm{C}$ ) at the constant electrical field frequency value of $1 \mathrm{kHz}$ for the PVC-P/NGK-NPs composites (differing concentrations). The results attributed the direct relationship between the A.C. conductivity and the temperatures and NGK-NPs concentration to the free charges which were available in this composite system. Furthermore, it was seen that at high temperatures, the mobility of the free charges was responsible for the frequency-dependent conductivity value [25, 26].

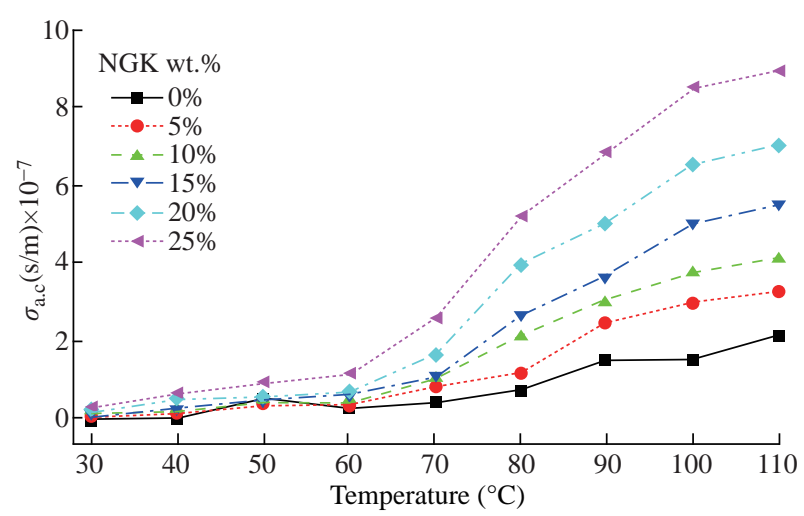

Fig. 8 The variation of $\sigma_{\text {a.c }}$ of PVC-P/NGK-NPs composites with temperature and filler content.

The study of the dependence of the A.C. conductivity value on the varying frequency values (ranging from $120 \mathrm{~Hz}$ to $2 \mathrm{MHz}$ ) for the NGK-NPs weight fractions at the room temperature is depicted in Fig. 9.

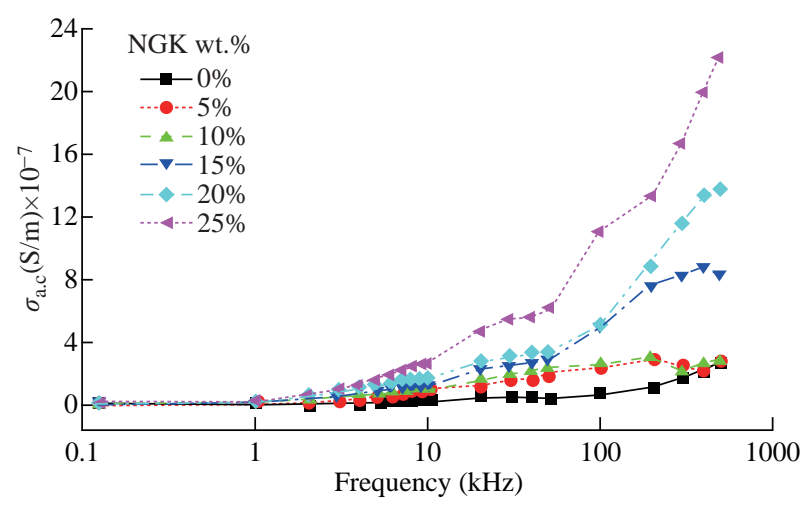

Fig. 9 The variation of $\sigma_{\mathrm{a} . \mathrm{c}}$ of PVC-P/NGK-NPs composites with frequency and filler content.

The graph shown in Fig. 9 indicated that this A.C. value increased with an increase in the filler content for all the frequency values that were studied. The increase in the A.C. conductivity was expected at a higher field frequency, with more impurities and when ions could be moved. This increased A.C. conductivity was attributed to the ionic interactions and the impurity movements in the electrolyte polymer composites.

In Fig. 10, we plotted the impedance (Z) for the PVC-P/NGK-NPs composites for varying temperatures (ranging between 30 and $110{ }^{\circ} \mathrm{C}$ ) for the different NGK-NPs weight fractions at the constant electric field frequency value of $1 \mathrm{kHz}$. It was seen that after the addition of the NGK-NPs filler powder, the impedance value could be decreased by increasing the temperature value. A decreasing impedance value was attributed to the higher motility of the segmental molecules with an increase in temperature.

Finally, the illustration in Fig. 11 presents the measured impedance of the composites with different NGK-NPs filler content (5, 10, 15, 20 and 25\% w/ $\mathrm{w})$ at room temperature and for different frequency values (ranging between $120 \mathrm{~Hz}$ and $2 \mathrm{MHz}$ ). The results indicated that for all the cases, the impedance value exponentially decreased with an increasing frequency and NGK-NPs concentration. This decrease was higher when the filler content was maximal. This

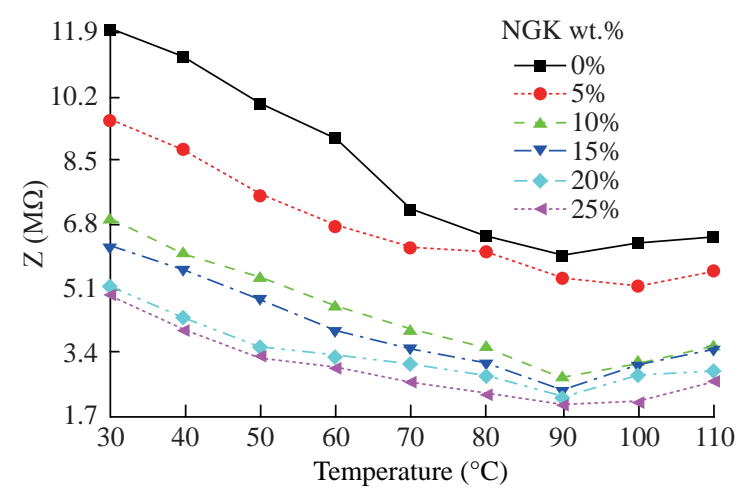

Fig. 10 The variation of impedance of PVC-P/NGK-NPs composites with temperature and filler content.

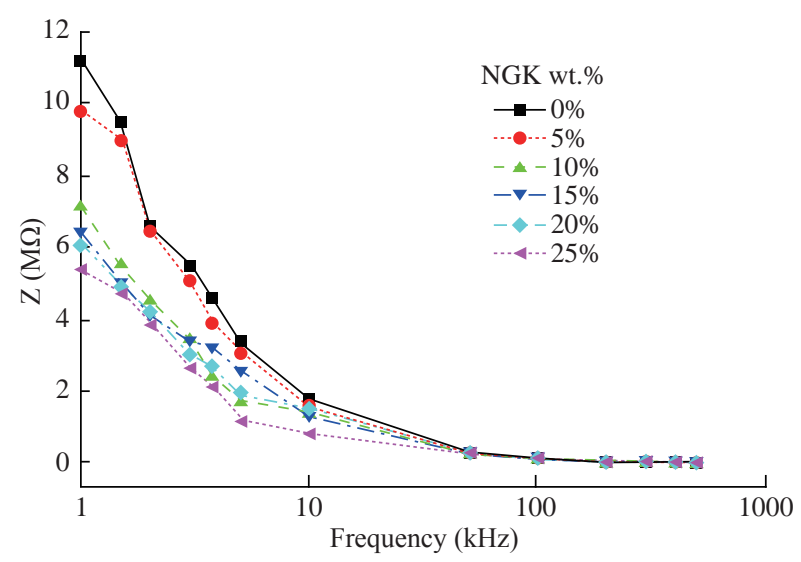

Fig. 11 The variation of impedance of PVC-P/NGK-NPs composites with frequency and filler content. 
decreasing impedance was attributed to increasing A.C. conductivity.

\section{Conclusions}

In this study, we investigated the frequency and the temperature dependence of the dielectric constant $\left(\varepsilon^{\prime}\right)$ and the dielectric loss factor $\left(\varepsilon^{\prime \prime}\right)$ for the PVC-P/NGKNPs composites for different frequency values (ranging between $120 \mathrm{~Hz}$ and $2 \mathrm{MHz}$ ) and differing temperatures (between 30 and $110{ }^{\circ} \mathrm{C}$ ). Experimental results indicated that the values of the $\varepsilon^{\prime}$ and $\varepsilon^{\prime \prime}$ increased after NGK-NPs were added to the PVC-P resin. At the low-frequency value, the permittivity decreased with an increasing frequency value; however, after the frequency value was increased beyond $100 \mathrm{kHz}$, these changes were ignored. Thereafter, an increase in the $\varepsilon^{\prime}$ at increasing temperatures was attributed to the higher freedom of the movement of dipoles of the polymeric molecular chains, which occurred at high temperatures. The dielectric loss noted in the composite materials at higher temperatures was ascribed to the glass transition temperature of the PVC-P materials. Lastly, the A.C. conductivity and the impedance value were seen to be temperature and frequency dependent.

\section{Acknowledgements}

This research work was supported by Department of Material Science, Polymer Research Centre, and by Department of Physics, College of Education for Pure Science, University of Basrah, Basrah, Iraq.

\section{References}

[1] R.J. Gutmann, Advanced silicon IC interconnect technology and design: Present trends and RF wireless implications. IEEE Transactions on Microwave Theory and Techniques, 1999, 47: 667-674.

[2] N.A. Inokawa, H. Yamamoto, E. Okazaki, et al., Evaluation of a Copper Metallization Process and the Electrical Characteristics of Copper-Interconnected Quarter-Micron CMOS. IEEE Transactions on Electron Devices, 1996, 43: 1206-1212.

[3] A.A. Edenfeld, D. Joyner, W.H. Kahng, et al., The National Technology Roadmap for Semiconductors Semiconductor Industry Association, 2001, 35: 42-53.

[4] J.H. Golden, C.J. Hawker, and P.S. Ho, Designing porous low-k dielectrics. Semiconductor International, 2001, 24: 79-87.

[5] Y. Xu, D.D.L. Chung, and C. Mroz, Thermally conducting aluminum nitride polymer-matrix composites. Composite: Part A, 2002, 32: 749-1757.

[6] P. Pezzotti, I. Kamada, and S. Miki, Thermal conductivity of AlN/polystyrene interpenetrating networks. Journal of the European Ceramic Society, 2000, 20: 1197-1203.

[7] H. Lee, K. Neville, Handbook of epoxy resins. McGrow Hill Book Company, London, 1967.

[8] M.J. Hodgin, R.H. Estes, Advanced boron nitride epoxy formulation excel in thermal management applications. Proceedings of the Technical Programs, NEPCON WEST 1999 Conference. Anaheim, CA, Feb. 23-25, 1999: 359366.

[9] B. Weidenfeller, M. HÖfer, and F. Schilling, Thermal and electrical properties of magnetite filled polymers. Composites Part A: Applied Science and Manufacturing, 2002, 33: 1041-1053.

[10] Y.P. Mamuny, V.V. Davydenko, P. Pissis, et al., Electrical and Thermal Conductivity of Polymers Filled with Metal Powders. European Polymer Journal, 2002, 38: 18871897.

[11] P.K.C. Pillai, G.K. Narula, and A.K. Tripathi, Dielectric Properties of Polypropylene/Polycarbonate Polyblends. Polymer Journal, 1984, 16: 575-578.

[12] X.C. Luo, D.D.L. Chung, Carbon-Fiber/Polymer-Matrix Composites as Capacitors. Composites Science and Technology, 2001, 61: 885-888.

[13] S.K. Wang, D.D.L. Chung, The Interlaminar Interface of a Carbon Fiber Epoxy-Matrix Composite as an Impact Sensor. Journal of Materials Science, 2005, 40: 18631867.

[14] P.G. Babaevsky, N.A. Kozlov, I.V. Churilo, et al., Influence of Simulated and Natural Space Environment Factors on Dielectric Properties of Epoxyamine Polymers and Polymer-Based Composite Materials. Cosmic Research, 2005, 43: 25-33.

[15] T. Tanaka, Dielectric Nanocomposites with Insulating Properties. IEEE Transactions on Dielectrics and ElectricalInsulation, 2005, 12: 914-928.

[16] S. Singha, M.J. Thomas, Permittivity and Tan Delta Characteristics of Epoxy Nanocomposites in the Frequency Range of $1 \mathrm{MHz}-1 \mathrm{GHz}$. IEEE Transactions on Dielectrics and ElectricalInsulation, 2003, 15: 2-11.

[17] V. Singh, A.R. Kulkarni, and T.R. Ramamohan, Dielectric Properties of Aluminum-Epoxy Composites. Journal of Applied Polymer Science, 2003, 90: 3602-3608.

[18] C.H. Kim, J.S. Shin, Dielectric Relaxation of SiloxanEpoxy Copolymers. Bulletin of the Korean Chemical Society. 2002, 23: 413-416.

[19] L. Ramajo, M.S. Catro, and M.M.E. Reboredo, Effect of Silane as Coupling Agent on the Dielectric Properties of $\mathrm{BaTiO}_{3}$-Epoxy Composites. Composites Part A: Applied Science and Manufacturing, 2007, 38: 1852-1959

[20] J.G. Hyun, S. Lee, and K.W. Paik, Frequency and Temperature Dependance of Dielectric Constant of Epoxy/ $\mathrm{BaTiO}_{3}$ Composite. Electronic Component and Technology Conference, 2005: 1241-1247.

[21] A. Muhammed, J. Athar, and Z.R. Tasneem, Dielectric Properties of Industrial Polymer Composite Materials. Turkish Journal of Physics, 2005, 29: 355-362.

[22] N. Hadik, A. Outzourhit, A. Elmansouri, et al., Dielectric Behavior of Ceramic (BST)/Epoxy Thick Films. Active and Passive Electronic Components. 2009, Article ID: 437130.

[23] A.A. Saq'an, A.S. Ayesh, A.M. Zihlif, et al., Physical Properties of Polystyrene/Alum Composites. Polymer Testing, 2004, 23: 739-745.

[24] K.C. Cheng, C.M. Lin, S.-F. Wang, et al., Dielectric Properties of Epoxy Resin-Barium Titanate Composites at High Frequency. Materials Letters, 2007, 61: 757-760.

[25] A.I. Medalia, Electrical Conduction in Carbon Black Composites. Rubber Chemistry and Technology, 1986, 59: 432-454.

[26] A.A. Hussain, W.A. Hussain, et al., Dielectric Properties of Epoxy/BaTiO ${ }_{3}$ Composites. Journal of Basrah 
Researches (Sciences), 2010, 36: 1-7.

Copyright $@$ Abdullah Hussein, Tahseen Alaridhee, and Forat Yasir AlJaberi. This is an open-access article distributed under the terms of the Creative Commons Attribution License, which permits unrestricted use, distribution, and reproduction in any medium, provided the original author and source are credited. 